\title{
Komunikasi Terapeutik Perawat Berhubungan dengan Kepuasan Pasien
}

\author{
Misi Siti' ${ }^{1}$ Zulpahiyana² $^{2}$ Sofyan Indrayana² \\ 1,2,3 Universitas Alma Ata Yogyakarta \\ Jalan Ringroad Barat Daya No 1 Tamantirto, Kasihan, Bantul, Yogyakarta \\ Email: zulpahiyana@gmail.com
}

\begin{abstract}
Abstrak
Komunikasi terapeutik merupakan komponen penting dalam keperawatan, komunikasi antar perawat dan pasien memiliki hubungan terapeutik yang bertujuan untuk kesembuhan pasien. Terciptanya komunikasi terapeutik yang baik akan menciptakan hubungan saling percaya antara perawat dan pasien. Dengan demikian, pasien akan merasa puas dan nyaman terhadap pelayanan yang diberikan perawat sehingga meningkatkan semangat dan motivasi pasien untuk sembuh. Penelitian deskriptif korelasi dengan rancangan cross sectional ini bertujuan untuk mengetahui hubungan komunikasi terapeutik perawat dengan kepuasan pasien di ruang rawat inap pringgodani RSU Rajawali Citra Bantul Yogyakarta. Jumlah sampel sebanyak 57 responden yang diperoleh secara accidental sampling. Analisis menggunakan uji alternatif yaitu uji kendal tau. Hasil penelitian ini menunjukkan 49,1\% komunikasi terapeutik perawat baik dan 68,4\% responden puas dan uji kendall tau menunjukkan $p=0,003$ dan nilai korelasi sebesar $r=0,371$. Kesimpulan ada hubungan yang signifikan Antara komunikasi terapeutik perawat dengan kepuasan pasien.
\end{abstract}

Kata Kunci: komunikasi terapeutik, perawat, kepuasan pasien

\section{Nurse's Therapeutic Communications is Related with The Patient's Satisfaction}

\begin{abstract}
Therapeutic communications is an important component in nursing, communication between nurses and patients have a therapeutic relationship that aims to cure the patient. The establishment of good therapeutic communication creates a relationship of trust between nurses and patients. Thus, the patient felt satisfied and comfortable with the services provided by nurses to improve the eagerness and motivation of the patient to recover. The aim of this research was to understand the nurse's therapeutic communication with patient's satisfaction in Pringgodani inpatient ward in Rajawali Citra Hospital Bantul, Yogyakarta. A total sample of 57 respondents were obtained by accidental sampling and used cross sectional design. Analysis in this study used kendall tau test. The result of this research showed that $49.1 \%$ nurse's therapeutic communication were good and $68,4 \%$ respondents felt satisfied and kendall tau test showed $p=0.003$ and correlation value is $r=0.37$. In conclusion, there was significant correlation between nurse's therapeutic communication and patient's satisfaction
\end{abstract}

Keywords: therapeutic comunication, nurse, patient satisfaction

Info Artikel:

Artikel dikirim pada 18 Oktober 2015

Artikel diterima pada 28 November 2015

DOI : http://dx.doi.org/10.21927/jnki.2016.4(1).30-34

\section{PENDAHULUAN}

Rumah sakitmempunyai fungsi penyelenggaraan pelayanan kesehatan salah satunya yaitu pelayanan keperawatan. Penyelenggaraan pelayananan keperawatan di Rumah Sakit ditentukan oleh tiga komponen utama antara lain jenis pelayanan yang diberikan, manajemen sebagai pengelola pelayanan dan tenaga keperawatan sebagai pemberi pelayanan keperawatan(1). Tenaga keperawatan atau perawat adalah seseorang yang telah lulus dari pendidikan 
perawat baik di luar maupun di dalam negeri yang telah diakui oleh pemerintah sesuai dengan perundang-undangan dan memiliki bukti yang tertulis berupa surat tanda registrasi(2).

Pelayanan keperawatan yang berkualitas tidak hanya ditentukan oleh ketepatan dalam memberikan pelayanan tetapi dengan membina hubungan komunikasi yang dapat menyebuhkan pasien (komunikasi terapeutik)(3). Perawat perlu memiliki keterampilan berkomunikasi secara terapeutik dalam menjalankan perannya sehingga dapat menentukan keberhasilan pelayanan atau asuhan keperawatan yang profesional dengan memperhatikan kebutuhan holistik klien(4). Kepuasaan pasien adalah suatu tingkat perasaan pasien yang timbul sebagai akibat dari kinerja dari layanan kesahatan yang diperoleh setelah pasien membandingkannya dengan apa yang diharapkan(5).

Menurut Depkes RI tahun 2005, masih ditemukan adanya keluhan tentang ketidakpuasan pasien terhadap komunikasi perawat. Rata-rata hasil data yang didapatkan dari beberapa Rumah sakit di Indonesia menunjukan $67 \%$ pasien yang mengeluh adanya ketidakpuasan dalam penerimaan pelayanan kesehatan(6).

Hasil studi pendahuluan yang dilakukan tanggal 15 April 2015, hasil wawancara yang dilakukan pada 2 orang perawat, didapatkan bahwa perawat sudah melakukan komunikasi secara terapeutik, meskipun telah dilakukan berdasarkan kebiasaan atau rutinitas sehari-hari tetapi belum sepenuhnya sesuai dengan harapan dari pasien. Hasil wawancara dilakukan pada 7 orang pasien, 3 orang pasien mengatakan puas, 4 pasien mengatakan kurang puas dengan komunikasi terapeutik perawat. Pasien mengatakan mereka merasa lebih dekat pada perawat-perawat yang menggunakan komunikasi dengan baik, dan bersikap ramah. Ada beberapa pasien yang kurang puas dengan pelayanan karena perawat tidak memperkenalkan diri terlebih dahulu, kurang ramah, dan komunikasi kurang baik ketika akan melakukan tindakan. Tujuan penelitian untuk mengetahui hubungan antara Komunikasi Terapeutik perawat dengan Kepuasan pasien di ruang Rawat Inap Pringgodani RS Rajawali Citra Bantul, Yogyakarta.

\section{BAHAN DAN METODE}

Jenis penelitian ini adalah deskriptif korelasi dengan pendekatan cross sectional yang dilakukan di Rumah Sakit Rajawali Citra Bantul, Yogyakarta pada bulan Juni 2015(7). Populasi dalam penelitian ini adalah seluruh pasien di ruang rawat inap Bangsal Pringgodani RS Rajawali Citra Bantul, Yogyakarta yang berjumlah rata-rata setiap bulannya 132 orang. Pengambilan sampel menggunakan teknik accidental sampling berjumlah 57 pasien yang di ruang rawat inap Pringgodani, bersedia menjadi responden, >24 jam dirawat, bisa membaca dan bisa menulis. Variabel independen (bebas) dalam penelitian ini adalah komunikasi terapeutik perawat. Variabel dependen (terikat) adalah kepuasan pasien. Perolehan data menggunakan data primer yaitu dengan dikumpulkan menggunakan kuesioner, dan data sekunder yaitu dengan melihat catatan-catatan medical Record(8). Kuesioner yang digunakan ada 2 yaitu: Komunikasi terapeutik dengan jumlah pernyataan yang dibuat sendiri oleh peneliti sebanyak 22 soal, dan kuesioner tingkat kepuasan pasien Jumlah pernyataan yang dibuat sendiri oleh peneliti sebanyak 22 soal. Kuesioner komunikasi terapeutik perawat dan tingkat kepuasan pasien dilakukan uji validitas $\mathrm{CVI}$ (Content Validity Index) dan Content Validity Ratio (CVR) Lawshe (1975). Dari hasil uji CVR dan CVI, didapatkan 22 butir pertanyaan valid. Data yang diperoleh kemudian dilakukan analisis menggunakan uji kendall tau.

\section{HASIL DAN BAHASAN}

Komunikasi terapeutik merupakan komunikasi profesional yang mengarah pada tujuan penyembuhan pasien(9). Dengan demikian Kepuasan pasien terjadi apabila apa yang menjadi kebutuhan, keinginan, harapan pasien dapat dipenuhi, maka pasien akan puas(3).

Berdasarkan Tabel 1 menunjukkan bahwa kepuasan pasien terhadap komunikasi terapeutik perawat sebagian besar berusia 36-45 tahun yaitu 14 orang $(24,6 \%)$. Kesehatan memiliki arti penting guna menunjang aktivitas para responden. Seseorang akan semakin mampu mengambil keputusan, lebih bijaksana, lebih mampu berpikir rasional. Lebih dapat mengedalikan emosi dengan bertambahnya usia. Hal ini dapat diketahui bahwa dengan usia yang bertambah kondisi fisik berkurang dan mudah sakit sehingga pemanfaatan fasilitas kesehatan semakin sering sehingga individu dapat menggunakan fasilitas kesehatan sesuia dengan harapan untuk mencapai kepuasan(10).

Berdasarkan kelompok jenis kelamin sebagian besar responden berjenis kelamin perempuan yaitu 31 orang $(54,4 \%)$. Pada dasarnya perempuan dan laki-laki memiliki gaya komunikasi yang berbeda. Jenis kelamin dapat mempengaruhi seseorang pada saat berinteraksi. Hal tersebut dapat mempengaruhi seseorang dalam menafsirkan pesan yang diterimanya(10). 
Tabel 1. Distribusi Frekuensi Karakteristik Komunikasi Therapeutik Perawat dengan Kepuasan Pasien

\begin{tabular}{lcr}
\hline \multicolumn{1}{c}{ Karakteristik } & $\mathbf{f}$ & \% \\
\hline Usia (tahun) & 7 & 12,3 \\
$17-25$ & 11 & 19,3 \\
$26-35$ & 14 & 24,6 \\
$36-45$ & 11 & 19,3 \\
$46-55$ & 7 & 12,3 \\
$56-65$ & 7 & 12,3 \\
>65 & & \\
Jenis Kelamin & 26 & 45,6 \\
Laki-laki & 31 & 54,4 \\
Perempuan & & \\
Pendidikan & 17 & 29,8 \\
SD & 5 & 8,8 \\
SMP & 23 & 40,4 \\
SMA/sederajat & 12 & 21,1 \\
Perguruan tinggi & & \\
Pekerjaan & 4 & 7,0 \\
Pelajar/mahsiswa & 9 & 15,8 \\
Tidak bekerja/ IRT & 39 & 68,4 \\
Wiraswasta & 5 & 100 \\
PNS & 57 & \\
Total & &
\end{tabular}

Sumber: Data Primer Tahun 2015

Ditinjau dari kelompok tingkat pendidikan sebagian besar responden tamat SMA yaitu 23 orang $(40,4 \%)$. Semakin tinggi tingkat pendidikan maka seseorang akan lebih mudah menerima dan mengelola pesan atau komunikasi dengan baik. Tingkat pendidikan seseorang akan berpengaruh terhadap gaya hidup dan pola fikir dalam mempertimbangkan sesuatu. Oleh karena itu, dengan pendidikan yang tinggi seseorang akan mampu menilai dan paham terhadap sesuatu termasuk dari kualitas pelayanan yang diberikan di RSU Rajawali Citra Bantul Yogyakarta(11).

Pekerjaan adalah kegiatan yang harus dilakukan seseorang dalam menunjang dan mempertahankan kehidupan dan kehidupan keluarganya. Pekerjaan erat kaitan dengan kejadian kesakitan dimana timbulnya penyakit melalui beberapa jalan yakni karena adanya faktor lingkungan yang dapat menimbulkan kesakitan yang penuh dengan stres, ada tidaknya gerak badan dalam lingkungan pekerjaan dan adanya kesibukan akibat pekerjaan(11). Hal ini berarti dapat diketahui bahwa dengan pekerjaan dapat menimbulkan kesakitan dan individu yang sakit akan menggunakan fasilitas kesehatan sehingga semakin sering menggunakan fasilitas kesehatan maka individu dapat menilai kualitas pelayanan tersebut(12). Berdasarkan Tabel 1 distribusi frekuensi karakteristik responden berdasarkan pekerjaan adalah non-PNS/ wiraswasta sebanyak 39 orang atau sebesar $(68,4 \%)$. Hasil ini mengindikasikan bahwa pekerjaan yang berat pekerjaan non-PNS (petani, buruh, pegawai pabrik atau swasta) merupakan pekerjaan yang menguras tenaga dan memerlukan fisik sehingga individu rentang terhadap penyakit baik fisik maupun psikologis(12).

Tabel 2. Distribusi Frekuensi Komunikasi Terapeutik Perawat

\begin{tabular}{lcc}
\hline Komunikasi Terapeutik & $\mathbf{n}$ & $\mathbf{\%}$ \\
\hline Baik & 28 & 49,1 \\
Cukup & 16 & 28,1 \\
Kurang & 13 & 22,8 \\
Total & 57 & 100 \\
\hline
\end{tabular}

Sumber: Data Primer Tahun 2015

Berdasarkan Tabel 2 diketahui bahwa mayoritas komunikasi terapeutik perawat di ruang pringgodani RSU Rajawali Citra Bantul Yogyakarta katagori baik sebanyak 28 orang $(49,1 \%)$, sedangkan komunikasi terapeutik perawat yang kurang baik sebanyak 13 orang $(22,8 \%)$. Sesuai dengan hasil penelitian Hajarudin juga mengatakan bahwa komunikasi perawat sebagian besar tergolong baik $(73,3 \%)(13)$.

Dari hasil penelitian dapat menunjukan, bahwa perawat telah konsisten menerapkan komunikasi terapeutik. Walaupun dari hasil peneltian ini yang menyatakan telah menerapkan komunikasi terapeutik yang baik, tetapi masih terdapat 13 responden $(22,8 \%)$, mengatakan kurang baik, hal ini harus mendapat perhatian serius dari perawat dalam penerapan komunikasi saat kontak pertama antara pasien dan perawat, sebab hal ini di buktikan dengan pernyataan pasien bahwa masih terdapat perawat yang tidak memperkenalkan diri kepada pasien.

Tabel 3. Distribusi Frekuensi Kepuasan Pasien

\begin{tabular}{lcc}
\hline Kepuasan Pasien & $\mathbf{n}$ & \% \\
\hline Sangat puas & 11 & 19,3 \\
Puas & 39 & 68,4 \\
Cukup puas & 7 & 12,3 \\
Total & 57 & 100 \\
\hline
\end{tabular}

Sumber: Data Primer Tahun 2015

Berdasarkan Tabel 3 diketahui bahwa mayoritas kepuasan pasien terhadap komunikasi perawat di Ruang Pringgodani RSU Rajawali Citra Bantul Yogyakarta kategori puas sebanyak 39 orang $(68,4 \%)$, sedangkan 7 orang $(12,3 \%)$ menyatakan cukup puas terhadap komunikasi terapeutik perawat.

Hasil penelitian ini tidak jauh berbeda dari penelitian yang dilakukan oleh Hajarudin yang menunjukkan sebagian besar tingkat kepuasan 
Tabel 4. Hubungan antara Komunikasi Terapeutik Pasien dengan Kepuasan

Pasien

\begin{tabular}{|c|c|c|c|c|c|c|c|c|}
\hline \multicolumn{9}{|c|}{ Kepuasan Pasien } \\
\hline \multirow{2}{*}{$\begin{array}{c}\text { Komunikasi } \\
\text { Terapeutik }\end{array}$} & \multicolumn{2}{|c|}{ Sangat Puas } & \multicolumn{2}{|c|}{ Puas } & \multicolumn{2}{|c|}{ Cukup } & \multirow[t]{2}{*}{$r$} & \multirow[t]{2}{*}{$p$-value } \\
\hline & $\mathbf{n}$ & $\%$ & $\mathbf{n}$ & $\%$ & $\mathbf{n}$ & $\%$ & & \\
\hline Baik & 9 & 15,8 & 18 & 31,6 & 1 & 1,8 & \multirow{4}{*}{0,371} & \multirow{4}{*}{0,003} \\
\hline Cukup & 1 & 1,8 & 14 & 24,6 & 1 & 1,8 & & \\
\hline Kurang & 1 & 1,8 & 7 & 12,3 & 5 & 8,8 & & \\
\hline Total & 11 & 19,3 & 39 & 68,4 & 7 & 12,3 & & \\
\hline
\end{tabular}

Sumber: Data Primer Tahun 2015

tergolong puas yaitu $(80,0 \%)(13)$. Penelitian lain juga yaitu Muri yang sebagian besar tingkat kepuasan tergolong puas yaitu $(89,6 \%)(14)$. Menurut Nursalam mengatakan bahwa kepuasan pasien apabila apa yang menjadi kebutuhan, keinginan, harapan pasien dapat dipenuhi, maka pasien akan puas(3).

Kepuasan adalah perasaan senang seseorang yang berasal dari perbandingan antara kesenangan terhadap aktivitas dan suatu produk dengan harapannya. Kepuasan adalah perasaan senang atau kecewa sesorang yang muncul setelah membandingkan antara persepsi atau kesannya terhadap kinerja atau hasil suatu produk dan harapan-harapannya(3).

Sesuai dengan teori di atas dapat diketahui bahwa semakin baik kualitas pelayanan yang diberikan rumah sakit maka tingkat kepuasan pasien juga akan meningkat, dan sebaliknya apabila kualitas pelayanan yang di berikan tidak baik maka kepuasan pasien akan menurun.

Berdasarkan Tabel 4 diketahui bahwa sebagian besar kepuasan pasien pada komunikasi terapeutik perawat yang baik sebanyak 18 (31,6\%). Berdasarkan uji statistik diperoleh nilai kendall tau dengan nilai $p$-value sebesar 0,003 yang berarti bahwa $p<0,05$ dapat disimpulkan bahwa terdapat hubungan bermakna komunikasi terapeutik perawat dengan kepuasan pasien. Hasil penelitian ini sesuai dengan hipotesis yang diajukan dalam penelitian ini yaitu ada hubungan komunikasi terapeutik perawat dengan kepuasan pasien di ruang rawat inap pringgodani RSU Rajawali Citra Bantul Yogyakarta.

Berdasarkan hasil uji $r$ di peroleh nilai $r=0,371$ nilai tersebut bisa disimpulkan bahwa kekuatan hubungan tergolong rendah, berada pada rentang nilai antara 0,20-0,399(15). Rendahnya keeratan hubungan antara komunikasi teraupetik dengan kepuasan pasien dikarenakan kepuasan tidak hanya dipengaruhi oleh komunikasi. Menurut Nursalamada, 11 faktor yang mempengaruhi tingkat kepuasan pasien yaitu: kualitas produk atau jasa, harga, kinerja, pelayanan, estetika, komunikasi, fasilitas, lokasi, suasana, desain visual, emosional, karakteristik produk(3).
Salah satu hal yang dilakukan perawat dalam menjaga kerjasama yang baik dengan pasien, maupun dengan tenaga kesehatan lain dalam rangka membantu memenuhi kebutuhan kesehatan pasien adalah dengan berkomunikasi. Dengan berkomunikasi perawat dapat mendengarkan perasaan pasien dan menjelaskan prosedur tindakan keperawatan(16).

Hasil penelitian ini dapat dijelaskan, bahwa sebagian besar responden menyatakan bahwa perawat telah menerapkan komunikasi terapeutik dengan baik dan sebagian besar pasien menyatakan telah puas dengan komunikasi yang diberikan oleh perawat. Semakin baik komunikasi terapeutik yang dilaksanakan maka semakin puas pasien dalam menerima. Sehingga dapat disimpulkan, bahwa komunikasi terapeutik berhubungan dengan kepuasan pasien.

Hasil penelitian ini didukung oleh penelitian yang dilakukan oleh Haryanto yang berjudul hubungan antara komunikasi terapeutik perawat dengan kepuasan pasien di Rumah Sakit Islam Kendal. Hasil penelitian ini didapatkan nilai $p=0,01(p<0,05)$ yang menunjukan bahwa ada hubungan antara komunikasi terapeutik perawat dengan kepuasan pasien(17). Sejalan juga dengan penelitian Tipo yang menyatakan bahwa komunikasi terapeutik yang diterapkan oleh perawat di Rumah Sakit Siti Khodijah mampu memberikan kepuasan kepada pasien selama dalam perawatan(18). Serta hasil penelitian Rahil yang menyatakan bahwa ada hubungan komunikasi terapeutik perawat dalam memberikan obat terhadap tingkat kepuasan pasien dalam pemberian obat di RSUD sleman, Yogyakarta(19).

\section{SIMPULAN DAN SARAN}

Gambaran komunikasi terapeutik perawat di ruang Pringgodani RSU Rajawali Citra Bantul Yogyakarta sebagian besar baik. Mayoritas kepuasan pasien di ruang Pringgodani RSU Rajawali Citra Bantul Yogyakarta puas terhadap komunikasi terapeutik perawat. Terdapat hubungan yang signifikan antara 
komunikasi terapeutik perawat dengan kepuasan pasien di ruang rawat inap Pringgodani RSU Rajawali Citra Bantul Yogyakarta. Dilihat dari nilai r menunjukan bahwa arah korelasi positif.

Perawat maupun tenaga kesehatan lainnya yang berada dalam lingkup RSU Rajawali Citra Bantul Yogyakarta, diharapkan dapat mempertahankan mutu pelayanan yang khususnya dalam bidang komunikasi terapeutik dan dapat meningkatkan penerapan komunikasi perawat pada saat berinteraksi dengan pasien maupun keluarga pasien. Pentingnya Profesi perawat (Ners) dalam mengembangan kompetensi komunikasi interpersonal dalam rangka meningkatkan mutu asuhan keprawatan yang diberikan pada pasien dan keluarga. Peningkatan kompetensi ini harus dilakukan dan disiapkan sejak proses pendidikan melalui pendidikan komunikasi interpersonal di kelas maupun melalui pelatihanpelatihan. Penelitian selanjutnya perlu menggali faktor lain yang dapat mempengaruhi kepuasan pasien selain komunikasi terpeutik.

\section{RUJUKAN}

1. Permenkes. Komite Keperawatan Rumah Sakit. Jakarta: Menkes RI; 2013.

2. Permenkes. Izin dan Penyelenggara Praktek Perawat. Jakarta: Menkes Rl; 2010.

3. Nursalam. Management Keperawatan Aplikasi dalam Praktek Keperawatan Profesional. Jakarta: Salemba Medika; 2014.

4. Nasir A, Muhith A, Sajidin M, Mubarak WI. Komunikasi dalam Keperawatan teori dan aplikasi. Jakarta: Salemba Medika; 2009.

5. Imbalo SP. Jaminan Mutu Layanan Kesehatan: Dasar-Dasar Pengertian dan Penerapan. Jakarta: EGC; 2007.

6. Departemen Kesehatan RI. Standar Pelayanan Minimal Rumah Sakit. Jakarta: Depkes RI; 2005.

7. Riyanto A. Aplikasi Metodologi Penelitian Kesehatan. Yogyakarta: Nuha Medika; 2011.
8. Notoatmodjo S. Metodologi Penelitian Kesehatan. Jakarta: Rineka Cipta; 2010.

9. Priyanto A. Komunikasi dan Konseling Aplikasi dalam Sarana Pelayanan Kesehatan untuk Berawat dan Bidan. Jakarta: Salemba Medika; 2009.

10. Potter PA, Perry AG. Buku Ajar fundamental keperawatan Konsep, Proses, dan Praktik. 4th ed. Jakarta: EGC; 2005.

11. Notoatmodjo S. Pendidikan dan perilaku kesehatan. Yogyakarta: Rineka Cipta; 2005.

12. Sondang PS. Kiat Meningkatkan Produktivitas Kerja. Jakarta: Rineka Cipta; 2009.

13. Hajaruddin. Hubungan antara Komunikasi Terapeutik dengan Tingkat Kepuasan Pasien di Puskesmas Pleret Bantul Yogyakarta [Internet]. Universitas Muhammadiyah Yogyakarta; 2014 [cited 2015 Jan 1]. Available from: http://thesis. umy.ac.id/ datapublik/t34289.pdf08.1809-32015.

14. Muri K. Hubungan Prilaku Caring Perawat dengan Tingkat Kepuasan Pasien di Bangsal Penyakit dalam kelas III RSUD Saras Husada Purworejo. STIKES Alma Ata; 2013.

15. Sugiyono. Statistika untuk Penelitian. Bandung: CP Alfabeta; 2011.

16. Mundakir. Komunikasi Keperawatan. Yogyakarta: Graha IImu; 2006.

17. Haryanto. Hubungan Komunikasi Terapeutik perawat dengan kepuasan Pasien di Rumah Sakit Islam Kendal [Internet]. 2009 [cited 2015 Aug 5]. Available from: http://jurnal.unimus.ac.id/255.

18. Tipo A. Hubungan Komunikasi Terapeutik Perawat dengan Kepuasan Pasien dalam Pelayanan Keperawatan di Rumah Sakit Siti Khodijah Sepanjang. SUN J Keperawatan. 2010;5(1):41-8.

19. Rahil NH. Hubungan Komunikasi Terapeutik Perawat dalam Memberikan Obat dengan Tingkat Kepuasan Pasien dalam Pemberian Obat di IRNA RSUD Sleman Yogyakarta. J IImu Keperawatan Respati. 2012;2(1):1-11. 